\title{
Extemporaneous Lessons on Place, Space, and Identity: Graffiti as a Pedagogical Disruption
}

\author{
Kaela Jubas, Kimberly Lenters
}

\begin{abstract}
In this interdisciplinary article, we employ scholarship from educational studies, cultural studies, geography, and sociology. We use graffiti texts we have encountered ourselves in places where we have lived or visited as examples of how graffiti becomes pedagogical. Theoretically, the concepts of public pedagogy, new mobilities, and affect theory — notably Sara Ahmed's ideas — complement Doreen Massey's ideas about place, space, and identity, and are cornerstones of our framework. As we consider them, pedagogy and learning are multidimensional processes, which involve intellect or cognition, affect or emotion, sensation, and perception. Place, space, and identity are taken up as sociomaterial phenomena, whose meanings develop as people, texts, physical structures, and various cultural artifacts come into contact with one another and with ideologies about what is (ab)normal and (un)desirable that circulate throughout and across societies. In presenting and discussing examples of graffiti texts we have encountered where we live or visit, we identify three pedagogical purposes that graffiti artists might employ: contemplation, reflection, and action. We close by considering implications for teaching and learning across disciplines, age groups, and context.
\end{abstract}

KEYWords Graffiti, public pedagogy, new mobilities, affect theory, literacies

In this article, we retrace our steps as pedestrians through places and spaces near to and far from home. What we have discovered, as we thought about our walks along streets and pathways, is that graffiti can be helpful to us in learning something about not only where we are, but also who and how we are (or ought to be or want to be). Following Doreen Massey's (1996) ideas, we consider how " "the spatial' is constituted by the interlocking of 'stretched out' social relations" (p. 22), so that place, space, time, and identity become intertwined. In turn, places give rise to personal identities (i.e., individuals are seen as belonging in or properly excluded from certain places; see also Cresswell, 1996) and entire places develop identities. Finally, we note that "the identity of a place-its social structure, its political character, its 'local' culture-is also a product of interactions" (Massey, 1996, p. 120). How people share space and develop practices in place can reflect, reinforce, challenge, and develop, in a Gramscian sense (Gramsci, 1971), ideologically based common sense about who and what are perceived as socially acceptable and desirable. In Tim Cresswell's (1996) words, place is "something produced by and producing ideology" (p. 17). Taking up these ideas, we aim to use graffiti images we have come across in cities where we have lived or visited to explore how graffiti can function pedagogically. More 
particularly, we are interested in how graffiti contributes to learning among passersby about how contemporary social issues and relations are (re)presented and (re)constructed locally and globally, materially and culturally.

Coincidentally, the two of us share a great deal in our histories of the places we have called home. Both of us were born in Toronto and continue to feel an attachment to that city. Later, we lived and went to university in Vancouver, on Canada's west coast - Kaela to study adult education and Kim to study youth literacy. Now, we are colleagues in Calgary, Alberta, just east of the Rocky Mountains. Whether for study or work or leisure, we have travelled to other cities and countries. In many of those places, we have been struck by forms of graffiti that are something other than gang-related tagging or seemingly simplistic degradation of property. Although we believe that all graffiti - like all use of public space — functions pedagogically, we are interested in graffiti texts that seem intentionally pedagogical, that aim to spread a message, to invite passersby into contemplation or discussion or call them to action. Such messages tell us something about the contemporary character of the places where we are or have been, about how the people who live there want to make and share their space, and about how we see ourselves in the sociomaterial context of space, place, and time.

This interdisciplinary article is grounded in scholarship from educational studies, cultural studies, geography, and sociology. Theoretically, the concepts of public pedagogy (Giroux, 2000, 2004; Luke, 1996), new mobilities (Sheller \& Urry, 2006), and affect theory — notably Sara Ahmed's (2010, 2015) work — complement Massey's (1996, 2004) ideas and are cornerstones of our framework. In the following sections, we conceptualize graffiti and outline our understanding of the key concepts and ideas which have framed our analysis and provide one illustration of community-engaged, arts-informed scholarship. We then present a series of images to illustrate how graffiti can invite those who encounter it into one of three sorts of learning processes that we refer to as contemplation, reflection, and action. In our closing section, we consider implications of our ideas for building and recognizing engaged teaching and learning processes, across age groups and educational settings. First, though, we spend some time conceptualizing graffiti and qualify the forms of graffiti that we included in our analysis.

\section{Graffiti in the Public and the Scholarly Landscape}

Graffiti has had a long history, which scholars can trace back to Ancient Rome (DeNotto, 2014; Garrofoni \& Laurence, 2013; Iddings, McCafferty, \& da Silva, 2011). What, though, are we talking about when we use that word, especially as educators and scholars? The word itself comes from the Italian verb, graffiare, which means "to scratch" (DeNotto, 2014, p. 208). Graffiti has been viewed as everything from children's scribbles to grown-up statements, from degradation of property to consideration of publicly visible spaces as blank canvases waiting to be filled. In separating graffiti "from the culture of the elite found in literary texts," scholars and everyday people alike who simply regard graffiti as "vulgar" overlook the possible "convergence of the two types of writing, and the fact that sections of literary texts [can] appear in graffiti" (Garrafoni \& Laurence, 2013, p. 125). 
Informed by perspectives from security and law enforcement, contemporary mainstream Western rhetoric about graffiti tends to tie it to vandalism, urban decay, and even obscenity. In North America, graffiti typically is discussed as "visible, invasive challenges to middle class and elite aesthetics, property concepts, and sense of security" (Christen, 2003, p. 57). Cresswell (1996) explains,

Just as dirt is supposed to represent not just a spoiling of the surface, but a problem that lies much deeper (in terms of hygiene, for instance), graffiti as dirt is seen as permanent despoiling of whole sets of meanings-neighborliness, order, property, and so on. Graffiti is linked to the dirty, animalistic, uncivilized, and profane. (p. 40)

In our current home base, the Calgary Police Service (2017) issues the following notice to the city's residents:

If not immediately removed, graffiti vandalism sends out a message that "nobody cares" about the area. It also causes the area to look unsafe and makes people concerned about their personal safety. This creates an open invitation for more littering, loitering and other graffiti. It may also lead to an increase in other crimes and/or acts of violence. (para. 3)

Despite that disparaging characterization, even the Calgary Police Service (2017) suggests there are different forms of graffiti, created for varied and not always nefarious purposes. On the same webpage, the Service notes that its emphasis is on graffiti "without permission" (para. 2), and that most graffiti texts are unrelated to organized gangs:

The most common type of graffiti vandalism is the Hip Hop graffiti which consists of hand scribbles, bubble type lettering or complex works. Communicative graffiti vandalism is about conveying a message, usually about political views. Hate graffiti vandalism is targeting a specific group with words that are threatening to that group. (para. 4)

In educational studies, that broader range of purposes is considered. Many adult educators working from a critical theory perspective and focused on social justice consider graffiti as a form of hate(ful) speech directed to members of marginalized social groups. Lyn Tett (2016; see also Crowther \& Tett, 2011) writes about her adult literacy education research with socioeconomically marginalized communities in the UK. One part of participants' learning was how to respond to racist graffiti in their neighbourhoods, including through collaborative letter-writing to politicians. In his research with lesbian, gay, bisexual, and queer (LGBTQ+) groups, Andre Grace (2016) recounts the ongoing reality that members of these communities encounter homophobic and transphobic graffiti.

A rather different emphasis is found in scholarship that explores graffiti as one of the deliberate tactics employed by activists who want to register and publicize a critique of the 
status quo. In adult education, this emphasis appears in work connected to social movement learning or art education; sometimes, these two areas are combined in scholarly work that explores graffiti as a form of both political and creative expression. With regard to the former area of work, Donna Chovanec (2006) recounts her research into women's pro-democracy activism in 1980s" Peru and notes the importance of "graffiti brigades" in resistance. Ana Iddings et al. (2011) describe similar uses of graffiti in São Paolo, Brazil.

Summarizing her international research into cultural institutions as sites of adult education, Darlene Clover (2015) explains that a graffiti artist was among the participants in a "Human Library" project based in Victoria, British Columbia. That project initiated exploration of and dialogue among participants about "misconceptions and stereotypes...that discourage them from seeing broader, problematic, sociopolitical constructions" (p. 306). Writing about their "pop-up art school" project conducted in Huddersfield, England, Christine Jarvis and Sarah Williamson (2013), who work with post-secondary students preparing to teach in art and design programs, note that graffiti surfaced as a form of expression that can be learned and used strategically. For one of the events focused on sustainability, the project brought students and community members together in learning techniques and using found materials to participate in collaborative art-making and discussion. Among the techniques that proved popular with participants, knitting was seen as more than a traditional craft; it was appreciated for its increasing appearance as the form of politically oriented graffiti known as "yarn bombing," often associated with feminist, peace or environmental movements (Larrie \& Newlands, 2017; Springgay, Hatza, \& O’Donald, 2012; Wallace, 2012). Another art educator, Steve Ciampaglia (2013) discusses graffiti as "guerilla art" and comments on his interest in graffiti texts that aim to "challenge cultural hegemony and authority" (p. 202). At the same time, he notes his surprise that students in his classes often overlook graffiti's political intention and are more likely to be captivated by "the creative visual stylizations employed by the graffiti artists" (p. 202).

Critical literacy scholar Elizabeth Moje (2000) takes up graffiti as one of many literacy practices through which people-including those who place or find themselves outside the idealized norm - construct novel, even if objectionable, ways of "exploring possible worlds, claiming space, and making their voices heard” (p. 651). As Moje establishes through her socioculturally informed research with U.S. gang-affiliated youth, graffiti can be seen as an "alternative or unsanctioned" (p. 653) literacy practice used to textually assert and read territorial and social claims. Likewise, cultural geographers bring a similarly critical eye to their analyses. Exploring the emergence of graffiti and the ensuing battles in 1970s' New York City, Cresswell (1996) describes graffiti as everything from "a symptom of the end of society, of anarchy and decaying moral values" to "a free spirit closing the curtain on the stifling bureaucracy" (p. 21).

\section{Stabilities and Movements}

Part of what makes graffiti so interesting to us is that it relies on a tension between location or stability, on the one hand, and movement or mobility, on the other. As we noted above, 
graffiti can seem anchored to a physical place and can have a lasting impact on social and material spaces. At the same time, graffiti texts have an inherently fleeting quality, sailing out of their original place as they are shared through photographs, removed or covered over. As Ana Iddings, Steven McCafferty, and Maria da Silva (2011) explain,

Some graffiti become famous and endure longer than others; some are close to where a person lives, a circumstance that allows multiple viewings across time; some are talked about and others not; some pertain to events that residents in general are aware of whereas others are targeted to a specific audience... and so forth. What is important to emphasize is that viewers are constantly exposed to graffiti over time and space as an everyday aspect of going about their lives in neighborhoods that are graffiti-active, sometimes for decades. (pp. 8-9)

Even movement and mobility, words used in 17th-century English onward to refer to different sorts of processes and phenomena (Cresswell, 2006), have tensions that make them interesting. In the sciences, the words have been used inter-changeably to refer to physical movement of bodies. Also in the sciences, movement can refer to certain bodily functions (e.g., bowel movement), while, in the social sciences, it has become attached to social agitation and transformation. According to Cresswell, "By the eighteenth century, the moveable and excitable crowd was known as the mobility (the mobile vulgus, in contrast to the nobility), later shortened to the mob" (p. 20, italics in original). Both words, then, can be used in celebratory fashion, to refer to capacity for advancement and change, even as they might signal disorder and danger. In the social sense that we use here, "the fact of movement becomes mobility" (Cresswell, 2006, p. 21).

In their discussion of multimodality and mobility, Kevin Leander and Lalitha Vasudevan (2009) consider how new technologies are bringing new approaches to culture, representation, and meaning. These new approaches acknowledge that space and identity are both material and discursive (Massey, 2004). Although they do so unevenly (Massey, 2004; Sheller \& Urry, 2006), new technologies facilitate the movement and hybridization of people and cultures; however, graffiti has always blurred the boundary between the vulgar and the refined by incorporating literary, political or social icons (Garrafoni \& Laurence, 2013). Like other examples of the new mobilities phenomenon, graffiti blurs the boundary between the static and the mobile, by relying on a combination of buildings, walls or other (infra)structures that are rooted in places and movement of people and texts across places (Sheller \& Urry, 2006). These new mobilities encompass movement of people and ideas, recognizes that how mobility is extended and experienced varies greatly depending on class, gender, racialized, national, and other identities, and attends as much to the nodes (Sheller \& Urry, 2006) through which people, places, and texts connect as to forms and processes of movement. So, movement and mobility are physical, social, and cultural.

Movement is also emotional. When they describe being moved by a dramatic or a poignant or a repugnant incident, people are articulating the idea that emotions move them from one 
state, one understanding, to another (Ahmed, 2010, 2015). That emotional movement is a form of learning. If movement can be thought of as emotional, though, emotion might also be thought of as "sticky" (Ahmed, 2015), as "about attachments or about what connects us to this or that" (p. 11). For Ahmed, emotion or affect is not just an individual phenomenon but, more importantly, socialized and politicized. She is interested in "the processes whereby 'being emotional' comes to be seen as a characteristic of some bodies and not others, in the first place. In order to do this, we need to consider how emotions operate to 'make' and 'shape' bodies as forms of action, which also involve orientations towards others" (Ahmed, 2015, p. 4). These emotional attachments are brought into encounters, which can play out in ways that would otherwise be inexplicable. This is the sense invoked by Cresswell (1996) when he explains that "something or someone belongs in one place and not in another. What one's place is, is clearly related to one's relations to others" (p. 3, italics in original). Following from this, far from a mindless scribble, graffiti has a complex of meanings and functions: It is found within, beyond, and across places, seen as in or out of place, experienced physically, intellectually, and affectively, and read as an individual point of view and a marker of social relations. Graffiti is more than an aesthetic intervention in place and space; it is a source and a form of text that, in being produced and read, becomes part of the community-engaged teaching and learning that unfolds, as we suggest in our title, extemporaneously.

\section{Graffiti as Public Pedagogue}

First introduced and popularized in the writing of Carmen Luke (1996) and Henry Giroux (2000, 2004), public pedagogy has become a term commonly used to denote the range of educational influences, settings, and processes that people encounter on an everyday basis. Largely associated with the scholarly field of cultural studies, public pedagogy is rooted in the older field of adult education, notably in the work of Raymond Williams. Williams' (1958/2011) famous statement that "culture is ordinary" (p. 179) anchors the notion that all cultural artifacts and accounts are forms of text, inasmuch as they require production and interpretation (Maudlin \& Sandlin, 2015), and that all texts are educative.

Like all education, public pedagogies are inherently socially and politically inflected, as they emerge "where people actually live their lives and where meaning is produced, assumed, and contested in the unequal relations of power that construct the mundane acts of everyday relations" (Giroux, 2000, p. 355). In Andrew Hickey's (2010) words, "the street operates as an implicit pedagogue ... [that] shapes us and influences our identity. ... The street comes to be a site of knowledges and discourses, in constant interplay and renewal, presented to us as we pass through" (p. 168). As graffiti creators, viewers, and even texts move through and across places and times, graffiti becomes one form of public pedagogy and one potential topic of engaged scholarship.

\section{Encounters with Graffiti}

Like the authors noted above, we understand the varied meanings and functions of graffiti, 
and employ a limited conceptualization of graffiti in this article. In this article, we take up an understanding of graffiti as:

.... literacy practice... [that] entails different ways of socially organizing communicative events involving written language and semiotic signs that can provide opportunities for access to social and cultural understanding. In this way, we were interested in the way people, "text," and context act on and interact with one another to produce meaning. (Iddings et al., 2011, p. 6)

In particular, we avoid references to obviously gang-affiliated markings or tags that present stylized names alone. We also avoid explicit slurs against minoritized social groups. What we do focus on is graffiti texts that can be interpreted as part of a deliberately engaged pedagogy aiming to foster some sort of personal or social progress. Finally, because this is a reflective analysis of our own encounters with graffiti texts, we focus on how critical adult and literacy education converge in everyday travels.

In our analysis, we read graffiti as different forms of invitation. Some graffiti texts seem to invite passers-by to respond through private, quiet contemplation. Others invite a more collective reflection, and still others extend an expectation for a form of critique and challenge that requires collective engagement and action. We discuss each of these forms of invitation in this section, offering examples of graffiti texts we have encountered and that we believe illustrate both producers' intentions and our own — that is, an audience's—reading of them.

\section{Contemplation}

Kim encountered what we came to call graffiti texts that seem aimed at moving passers-by into a contemplative process on walks along the Bow River pathway, which runs along some of Calgary's inner-city neighbourhoods (see Figure 1). A popular destination for cyclists, joggers, and walkers of all ages, the pathway affords views of the river and stands of trees, and is dotted with a couple of islands that have been developed as pedestrian-only parks. Running parallel to the downtown core, much of the path offers an alternative to streetscapes of high rises and vehicular traffic. It is a space where people might find it easy to slow down and enjoy an outdoor setting that blends the urban and the natural. 

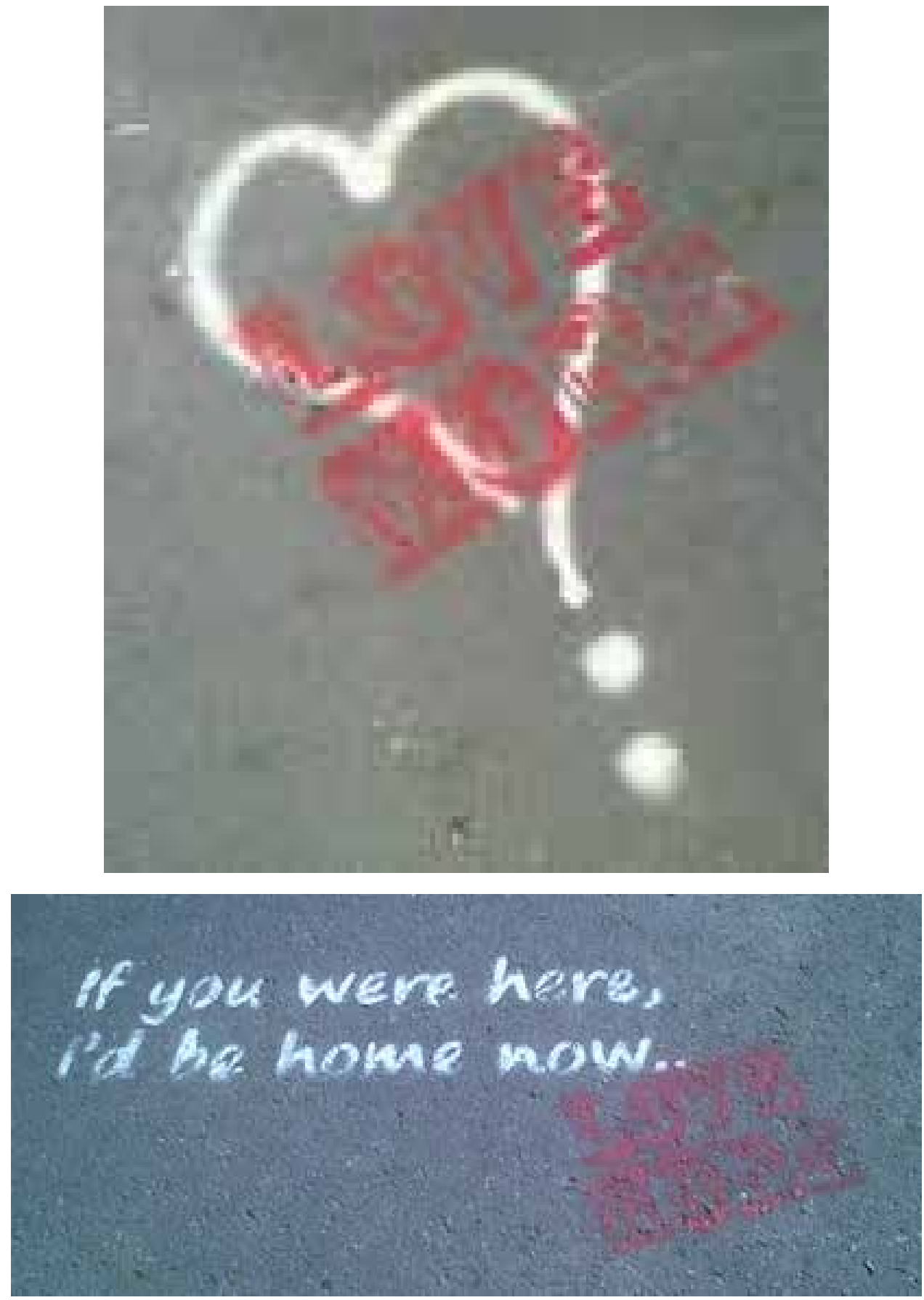

Figure 1. Calgary, AB Bow River pathway images Photos: Kimberly Lenters 
With their messages of "Love more," "Live the life you [love,] love the life you live," and "If you were here, I'd be home now. Love more," these messages, stencilled on concrete sections of the river pathway, seemed to call out to those who encounter them in particular ways. Over a period of several years, these messages could be found in numerous places along the pathway system, making them everyday encounters (Iddings et al., 2011) for many who use the paths for commuting and recreation.

Although such texts appeared in public spaces, they seemed aimed at fostering a private, individual process of contemplation. Even in their somewhat cryptic messages, they suggested that pausing to take stock of what and who is important and valued is an important and worthwhile interruption to everyday comings and goings. These texts functioned as what Ahmed (2010) refers to as "happy objects," which "accumulate positive affective value as they are passed around" (p. 29) or encountered. The heart-shaped symbol, the printed word LOVE, the suggestion of a loving partner who makes any place feel like home-these all transmitted a culturally defined sense of desire and, if that desire is fulfilled, sense of wholeness and wellness. Moreover, these texts worked in the context of place-the relaxed riverside pathway along which cyclists and pedestrians experience a unique assemblage of nature-in-the-city.

Although the application of the graffiti might be illegal, the feelings that these texts generated did not include the fear and disgust that might typically be associated with graffiti. On the contrary, as Ahmed (2010) suggests, the physical placement of these texts capitalized on the likelihood that people who already felt happy would attribute additional happiness to the graffiti. Moving and coming together, spatially and temporally, text, place, graffiti producer and viewer constructed a sense of place and self in place.

In the process of contemplation and production of the contemplative self these texts invited, there was no hint that viewers should move beyond quiet appreciation. Moreover, returning to Ahmed's $(2010,2015)$ ideas about the social nature of emotion, we wonder how a general call to love is taken up in the context of other messages about who is loving and lovable. In these texts, there is no invitation to consider why some people might find it easier than others to give, receive, and share love, happiness, and contentment. That process is associated with a second form of graffiti texts, which we contend invite reflection.

\section{Reflection}

As the two of us undertook this project, Kim began to reconsider the graffiti presented in Figure 1. We talked about the contemplative process encouraged by those texts, and she wondered about their function. In her words,

What registered for me as a virtual tsunami of happy stencils when I first came to Calgary left me contemplating: Why so many here in Calgary? Why so many with the "love" message? Might these happy objects also serve the pedagogical purpose of promoting the Calgary can-do spirit, culture of old/new west "boosterism"?

This response suggests how personal contemplation can be extended by a deeper, more 
critical process, which we refer to as reflection. In contrast to inward-focused contemplation, reflection entails a shift in focus outward, an explicit claim in and on public space, and a rethinking what is understood as within/out place. Such a reflective process seems apparent in the following examples of graffiti texts we have encountered.

One issue that has attracted a great deal of attention among publics in recent years is consumption. From concern about environmental impact to the sustainability of locally operated businesses to food security, the encroachment of transnational policies and corporations has

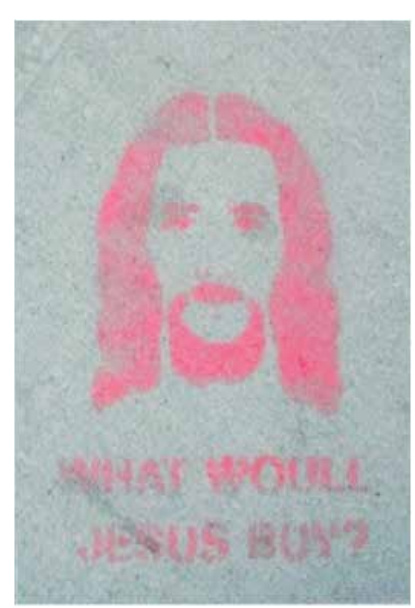

Figure 2. Victoria, BC downtown sidewalk image Photo: Kaela Jubasrouge given rise to various organizations and movements. Like graffiti texts, which are both in place and mobile, references to localized circumstances and globalized processes, consumption-related movements develop in and across place. In the next two figures, we present examples of consumption-related graffiti that seem to invite viewers into a reflective stance.

The first of these graffiti texts was encountered by Kaela in 2008 on a well-travelled sidewalk dotted with interesting, independently operated shops and eateries in Victoria, British Columbia (see Figure 2). Gazing into a simply rendered but solemn bearded face, the viewer was asked, "What would Jesus buy?" With that question, posed in the midst of a popular shopping district, the graffiti artist seemed to be inviting viewers to think about their shopping and consumption practices, and consider what impulses and purposes they fulfill, and how those practices ultimately function spiritually, ethically, and socially. This text, too, operated affectively. Although the image and name of Jesus dominate the text, Kaela saw an emphasis on a general feeling of spiritual (dis) satisfaction rather than an affiliation with any particular religion or doctrine.

Continuing to use the rhetoric of consumerism, which positions everything as available for purchase and use, a second graffiti text invited passers-by to reflect on the surrender of hope and vision. In this example, a "for sale" sign was altered to express a perception that young people are "selling out" on their principles and their commitment to building a better future (see Figure 3). The sign was spotted by Kaela's partner in the fall of 2017, posted on the fence of a lot near the home they maintain in Victoria, BC. That neighbourhood might be described as "in transition": It houses a people of varied incomes. With homes ranging from highend condominiums to rental apartments, it also has several subsidized or supported housing projects and a shelter for homeless people. In the fairly small city of Victoria, it is unique for the mix that light industry, including a number of artisan studio shops and breweries, adds to the neighbourhood homes and services. It also has the perk of lovely views and a walking and bicycle trail that runs along the Gorge waterway. Since Kaela has had a home in this part of town, it has seemed like a neighbourhood with a conscience, one that "steps up" in responding to social and environmental issues. A nearby park is a base for families with young children and youthful festivals focused on anything from the annual Gorge swim fest to a smaller, quirky 
music festival powered by generators connected to bicycles. This is a part of the city where community members are not shy about making their views known.

Like all cultural texts, these two examples of graffiti were produced and read intertextually, in juxtaposition with one another and with multiple other texts. The message, presumably from a young person, that idealism, which has always seemed to be the purview of youth, is being abandoned, seemed to go beyond the invitation to reflect on hyper-consumerism presented above. Here, we see the conjuring of a despairing affect accompanying an invitation to reflect on the dreams and potential of an entire generation that are being bought and sold as corporations focus on their profit margins and governments withdraw from their social commitments.

Any encounter with individual texts, including these examples of graffiti, "plunges us into a

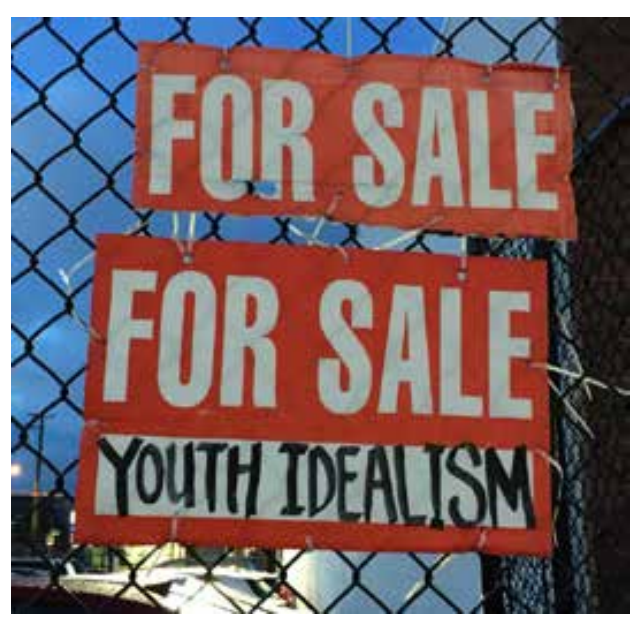

Figure 3. Victoria BC street sign Photo: Karen Caithness network of textual relations. ... Reading thus becomes a process of moving between texts" (Allen, 2011, p. 1). These two graffiti texts appear(ed) in different parts of the same city and in different years, marking areas and years in particular ways; however, they also knit those places and times together, reminding Kaela, along with other viewers and readers that issues and texts are made and received within and across places, spaces, and times. Long since removed or worn away, the "What would Jesus do?" graffiti text returned to Kaela's thoughts when she encountered the modified "For sale" sign a few years later, as a reminder of the ubiquity not just of consumption but also of the anti-consumerist framing of concerns.

Kim experienced a second example of graffiti text inviting reflection on a sidewalk in the

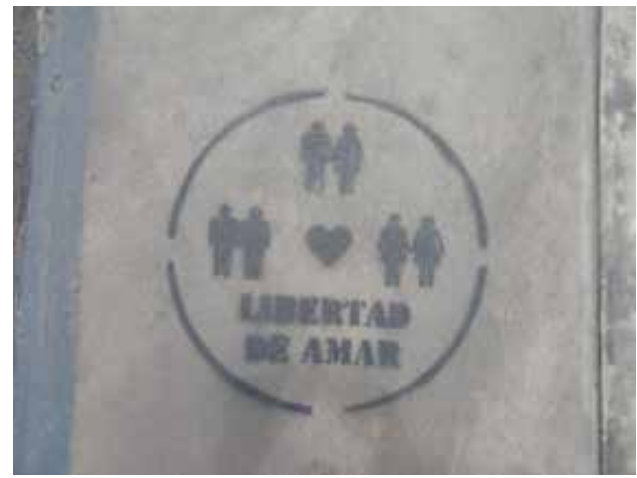

Figure 4. Lima, Peru sidewalk image outside a major Catholic church Photo: Kimberly Lenter
Mira Flores district of Lima, Peru in April 2015 (see Figure 4). Although its focus was different from the two examples discussed above, it too illustrated how graffiti can enter into social debate that circulates globally, but with local nuances. It also provides a good example of how graffiti is produced and read intertextually. This particular sidewalk follows the coastal cliff bordering Lima's western edge. It serves as a curved dividing-line between high-rise residential and retail spaces and the recreational parkland that forms the boundary between city and ocean. Stencilled on a section of the sidewalk, across the street from a Roman Catholic church, the message in Spanish stated, 
"Libertad de amar," or translated into English, "Freedom to love." Graphics expanded this message with a heart in the centre of a permeable circle and three couples (male-male, malefemale, female-female) situated around the heart.

The message proclaimed freedom to love whomever we will love, regardless of gender and sexual identity. Found in another space we argue it might have invited quiet contemplation; however, its actual location outside a Catholic church in a country where Catholicism retains cultural currency, urged more than inward-focused contemplation-it invited the viewer to reflect on how a globalized movement to extend rights to and acceptance of lesbians and gay men. Through its location, the quiet stencilled statement, facing a church whose doctrine explicitly limits marriage to heterosexual couples, made visible the politics of love. It both acknowledged and disrupted the rootedness of the $\mathrm{C} /$ church and claimed a space for relational diversity and sexually marginalized people in the vast city of Lima, Peru.

\section{Action}

In this final selection of graffiti, we see another shift, as invitations to reflection become invitations to action. Beyond encouraging viewers to think about relations and complicities, these texts suggest how viewers can translate analysis and critique into changed practice. As the focus seems to change, so too does the tone of the invitation, which becomes more pressing, something closer to a calling.

Kaela came upon one of these texts in Sydney, Australia in 2006, at the start of a day trip to the Blue Mountains. Plainly visible on the walkway leading to the city's Central train station, where it would be visible to thousands of people daily, the simple text issued an ominous comment about the dangers of silence in the face of unfettered consumerism (see Figure 5). Evoking a Marxist sensibility, the text portrayed human beings as drones who give themselves — ourselves — over to the obligations of work and the distractions of consumption. In the process, this graffiti implied, any meaning in life is scarificed. Of course, some sort of work and consumption are necessary in life, and it is a fact that we all will die. What remains changeable is silence. In inserting the "Be silent" phrase, this text disrupted the "natural," common sense order of things and suggested we all have agency, because we all have voices. Although similar in some respects to the "For sale-Youth idealism" image discussed above, to us, this text seemed to take an affective tone of indignant challenge rather than resigned satire.

Kaela saw a second action-oriented graffiti text while visiting Aveiro, Portugal in 2011. This graffiti, painted on a wall outside the small city's train station, notified passersby about a nation-wide general strike organized for the following day (see Figure 6). In inviting people to participate in the strike, this text

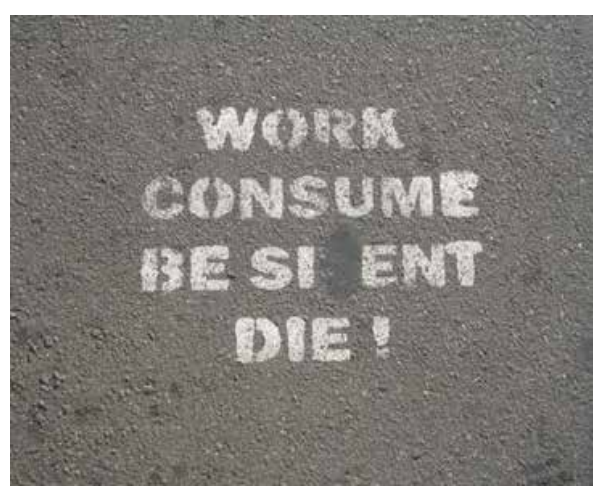

Figure 5. Sydney, Australia image on the sidewalk outside the Central train station Photo: Kaela Jubas 


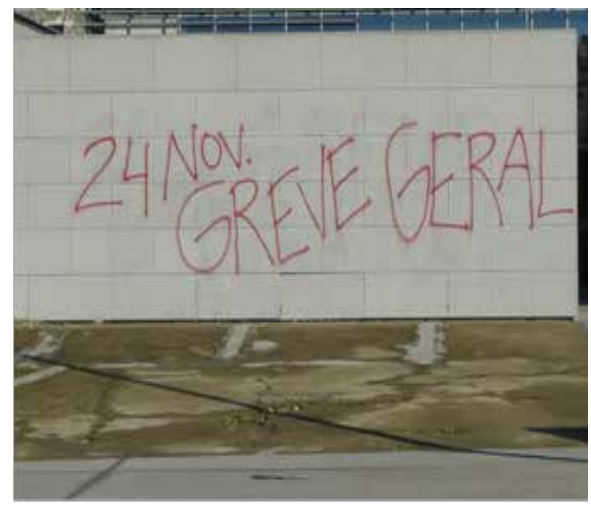

Figure 6. Aveiro, Portugal-Call to general strike on the train station wall Photo: Kaela Jubas reminded people that, in body and voice, they could join others in contributing to social change. The lesson of the graffiti moved off the wall, as Kaela's vague sense of the opposition to austerity measures was deepened by conversations with the local conference coordinator about the extent of citizen anger over the impacts of government cut-backs, which had reached even this fairly conservative city.

Affectively, both of these graffiti texts summoned feelings of anger, directed at systems and practices that diminish human dignity and well-being. They disrupted the plans for the day, whether attending a conference or beginning a pleasant jaunt. They were also more than expressions of outrage; in issuing invitations to action, they taught viewers something about contemporary politics and social movements, and might have reminded some viewers that, raised in protest against the status quo and insistence of something more sustainable and just, our voices can contribute to the making of a different life, a different social condition, a different text.

\section{Bringing It Home: Closing Thoughts}

We have argued here that at least some graffiti aims to reach the ordinary passerby with a political or social message and that, as it does so, it performs a pedagogical function. Not every graffiti text accomplishes this in the same way, though, or tries to convey the same kind of message. Certainly, there are examples of graffiti meant to offend and conjure hatred through expressions of bigotry, examples meant to intimidate residents and rivals by marking territory as gang-controlled, and examples meant to do little more than boost the egos of taggers. Those were not the sorts of graffiti that we chose to consider here. Instead, we presented examples of graffiti that, we believe, intend to invite viewers into responses we conceptualized as contemplation, which brings the gaze inward, reflection, which relates the individual to the social, and action. Differences are affective more than topical, and made apparent in in the graffiti's aesthetics and explicit messages.

Grounded in place, space, and time, graffiti also becomes unmoored from its physical and temporal location as it is shared online or in print with viewers elsewhere. Graffiti's producers, viewers, and texts find one another in place and time, and are (re)moved in ways that can be planned or unimagined. Even viewers who do not take up graffiti's invitations for contemplation, reflection or action might notice a text and move on from it as altered, emotionally moved individuals. Similarly, the place in which graffiti is located is altered; its social structure and political character, its very identity becomes "a product of interactions" (Massey, 1996, p. 120) with(in) it. In this way, graffiti works as more than an informal pedagogue; it becomes a catalyst, producing change in those who interact with it and the very place in which it is located as well as a possible resource for educators working either in the formal classroom 
or engaged in community-based education.

In some places, municipal planning staff or private landowners have hired artists to transform surfaces in public or publicly accessible spaces by creating murals and, presumably, to decrease the appeal to graffitists of otherwise-blank surfaces. Such moves signal attempts to restrain what some see as citizen outbursts and degradation of property and control the ways in which spaces are enhanced aesthetically. While such responses may be portrayed as necessary for the maintenance of urban social order, they disregard the potential cultural and intellectual sophistication and refinement that graffiti can have (Garrofoni \& Laurence, 2013), as well as the pedagogical impetus of graffiti texts that issue invitations to contemplate, reflect on, and act on issues of personal well-being and perceived social injustices.

Although we had no community partners in this work, we see the artists and the graffiti discussed above and our discussion of them as contributions to various efforts to understand, build, and advance community through an artful practice. We offer this article as an engagement in the conversation about the function of graffiti in community and in our own efforts in engaged teaching and scholarship.

\section{Acknowledgements}

This manuscript is based on a presentation delivered at the Popular Culture Association of Canada 2014 conference. We thank those in attendance at that session for their engaged, probing questions. Thanks as well to Karen Caithness for agreeing to have her photo included in this article. We also thank the editors for organizing and welcoming us into this special issue, and the reviewers for their careful reading of our submission.

\section{About the Authors}

Kaela Jubas (corresponding author) is an associate professor in Adult Learning at the Werklund School of Education, University of Calgary. In her research, she explores varied community settings and contexts as sites of learning: the workplace, cultural and material consumption, social movements, as well as the post-secondary classroom itself. In a current SSHRC-funded project, she is investigating the use of popular culture in professional education to foster learning about concepts and theories or contentious, "difficult" issues and, in a smaller project, how students and instructors engaged in professional education are learning about and taking up messages from the \#Me'Too movement. Email: kjubas@ucalgary.ca 
Kimberly Lenters is an associate professor at the Werklund School of Education and Associate Dean at the Faculty of Graduate Studies, University of Calgary. Informed by a critical posthuman perspective on literacy, Kim's work examines literacy practices as enacted in networks of people, objects and practices. Funded by a SSHRC Insight Development Grant, Kim's most recent project examines the possibilities of improvisational comedy (Improv) for language arts instruction in the elementary school classroom.

\section{References}

Ahmed, S. (2010). Happy objects. In M. Gregg \& G. J. Seigworth (Eds.), The affect theory reader (pp. 29-51). Durham, NC \& London, England: Duke University Press.

Ahmed, S. (2015). The cultural politics of emotion (2nd ed.). New York, NY: Routledge.

Allen, G. (2011). Intertextuality (2nd ed.). New York, NY: Routledge.

Ciampaglia, S. (2013). Guerilla art action: Taking it to the street with teenage students. Harvard Educational Review, 83(1), 201-210.

Calgary Police Service. (2014). Graffiti-free Calgary. Retrieved November 7, 2017 from http://www. graffitifreecalgary.ca/what-is-graffiti-vandalism.php

Chovanec, D. M. (2006). Between finding ourselves and losing ourselves: The consequences of social movement participation [Roundtable paper]. In L. English \& J. E. Groen (Eds.), Proceedings of the Canadian Association for the Study of Adult Education/L'association canadienne pour l'etude de l'éducation des adultes 25 th Annual Conference (pp. 254-255). Toronto, ON: York University. Retrieved from http://www.casae-aceea.ca/

Christen, R. S. (2010). Graffiti as public educators of urban teenagers. In J. A. Sandlin, B. D. Schultz, \& J. Burdick (Eds.), Handbook of public pedagogy: Education and learning beyond schooling (pp. 233-243). New York, NY \& London, England: Routledge.

Clover, D. E. (2015). Adult education for social and environmental change in contemporary public art galleries and museums in Canada, Scotland and England. International Journal of Lifelong Education, 34(3), 300-315.

Cresswell, T. (1996). In place/out of place: Geography, ideology, and transgression. Minneapolis, MN: University of Minnesota Press.

Cresswell, T. (2006). On the move: Mobility in the modern Western world. New York, NY \& London, UK: Routledge.

Crowther, J., \& Tett, L. (2011). Critical and social literacy practices from the Scottish adult literacy experience: Resisting deficit approaches to learning. Literacy, 45(3), 134-140.

DeNotto, M. (2014). Street art and graffiti: Resources for online study. College and Research Libraries News, 75(4), 208-211.

Garrafoni, R. S., \& Laurence, R. (2013). Writing in public space from child to adult: The meaning of graffiti. In G. Sears, P. Keegan, \& R. Laurence (Eds.), Written space in the Latin West, 200 BC to AD 300 (pp. 123-134). London, UK \& New York, NY: Bloomsbury.

Giroux, H. A. (2000). Public pedagogy as cultural politics: Stuart Hall and the "crisis" of culture. Cultural Studies, 14(2), 341-360. 
Giroux, H. (2004). Cultural studies, public pedagogy, and the responsibility of intellectuals. Communication and Critical/Cultural Studies, 1(1), 59-79.

Gramsci, A. (1971). Selections from the prison notebooks (Q. Hoare \& G. Nowell Smith, Eds. \& Trans.). New York, NY: International Publishers.

Hickey, A. (2010). When the street becomes a pedagogue. In J. A. Sandlin, B. D. Schultz, \& J. Burdick (Eds.), Handbook of public pedagogy: Education and learning beyond schooling (pp. 161-170). New York, NY: Routledge.

Iddings, A. C. D., McCafferty, S. G., \& da Silva, M. L. T. (2011). Conscientização through graffiti literacies in the streets of a São Paulo neighborhood: An ecosocial semiotic perspective. Reading Research Quarterly, 46(1), 5-21.

Jarvis, C., \& Williamson, S. (2013). University teacher education and the pop-up art school. In D. E. Clover \& K. Sanford (Eds.), Lifelong learning, the arts and community cultural engagement in the contemporary university: International perspectives (pp. 54-66). Manchester, England: Manchester University Press.

Leander, K. M., \& Vasudevan, L. (2009). Multimodality and mobile culture. In C. Jewitt (Ed.), The Routledge handbook of multimodal analysis (pp. 127-139). New York, NY: Routledge.

Luke, C. (Ed.). (1996). Feminisms and pedagogies of everyday life. Albany, NY: State University of New York.

Massey, D. (1996). Space, place and gender. Minneapolis, MN: University of Minnesota Press.

Massey, D. (2004). Geographies of responsibility. Geografiska Annaler, 86B(1), 5-18.

Maudlin, J. G., \& Sandlin, J. A. (2015). Pop culture pedagogies: Process and praxis. Educational Studies, 51(5), 368-384.

Moje, E. B. (2010). "To be part of the story": The literacy practices of gangsta adolescents. Teachers College Record, 102(3), 651-690.

Rahn, J. (2002). Painting without permission: Hip-hop graffiti subculture. Westport, CT: Bergin and Garvey/ Greenwood.

Sandlin, J. A., Schultz, B. D., \& Burdick, J. (2010). Understanding, mapping, and exploring the terrain of public pedagogy. In Handbook of public pedagogy: Education and learning beyond schooling (pp. 1-6). New York, NY: Routledge.

Sheller, M., \& Urry, J. (2006). The new mobilities paradigm. Environment and Planning A, 38, 207-226.

Tett, L. (2016). Community-based education and learning. In J. Field, B. Schmidt-Hertha, \& A. Waxenegger (Eds.), Universities and engagement: International perspectives on higher education and lifelong learning (pp. 130-140). London, UK: Routledge.

Wallace, J. (2012). Yarn bombing, knit graffiti and underground brigades: A study of craftivism and mobility. Wi: Journal of Mobile Media, 6(3). Retrieved from http://wi.mobilities.ca/

Williams, R. (2011). Culture is ordinary. In I. Szeman \& T. Kaposy (Eds.), Cultural theory: An anthology (pp. 53-59). Malden, MA: Wiley-Blackwell. (Original work published 1958)

Wright, R. R., \& Sandlin, J. A. (2009). Cult TV, hip hop, shape-shifters, and vampire slayers: A review of the literature at the intersection of adult education and popular culture. Adult Education Quarterly, 59(2), 118-141.

Engaged Scholar Journal: Community-Engaged Research, Teaching, and Learning 